\title{
23
}

\section{Virtualizing the Virtual}

\author{
Neil C. Ramiller \\ School of Business Administration, Portland State University \\ P.O. Box 751, Portland, OR, USA 97207-0751 \\ neilr@sba.pdx.edu \\ WWW home page: \\ http://www.sba.pdx.edu/faculty/neilr/nraccess/webpage_main.htm
}

\begin{abstract}
This essay advances a supplementary definition of "the virtual" that is aimed at helping our research community speak more clearly to the organizational changes and the place-time reinventions taking place in connection with the virtual in the more customary sense(s) of that term. The intent in linking the issue of definition to organizational transformation is not to make proposals about the specific forms, functions, and reinventions that might, or ought to, appear, but rather to reflect on the processes through which such changes, whatever their character, come about. Adapting Deleuze's conceptualization of the virtual, I extend virtuality to include the imaginary and fictitious. The focus, in particular, is on the kind of fiction that, in Latour's phrasing, is "seeking to come true"; thus, our interest is in the fictionalizations in which real actors engage as they struggle discursively to construct their future realities. This calls for attention to the social and political context and, more specifically, to the manner in which the privileges of "author-ity," for fictionalization, impact what is actualized as organizational structure and practice. The paper concludes with a consideration of the implications for research practice of viewing IT-enabled change, like that which is producing virtual work and virtual organizations, as a form of authorship.
\end{abstract}

\section{Introduction}

it cannot be denied that many stories, especially those called novels, may be regarded as possible, even if they do not actually take place in this particular sequence of the universe which god has chosen...

Leibniz, quoted by David Harvey [1]

Please use the following format when citing this chapter:

Ramiller, N.C., 2007, in IFIP International Federation for Information Processing, Volume 236, Virtuality and

Virtualization; eds. K. Crowston, Sieber, S., Wynn, E., (Boston: Springer), pp. 353-365. 
The conference's Call for Papers employs some familiar characterizations of the virtual, but also advances as one of the possible topics for discussion, "defining virtuality." In this paper I propose to amplify and extend the definition of the virtual (and virtuality) in a way that can help us speak more clearly to two of the other suggested topics, "virtuality and changing organizational form and function" and "reinvention of place and time associated with virtualization." The intent in linking the issue of definition to these latter concerns will not be to make proposals about specific forms, functions, and reinventions that might, or ought to, appear, but rather to reflect on the process through which such changes, whatever their character, come about.

What I aim to do is to take the concept of the virtual beyond the confined reach of its usual realist connotations and, as such, beyond the boundaries of everyday space and time, to add a dimension that extends the virtual to include the imaginary and fictitious. This is not nearly as outlandish as it might sound. Seeing why will depend on understanding the relationship that fiction, in the context of organizational innovation, has to the (re)constitution of the future-including reinvention and change of the sort that the Call for Papers invokes in the name of the virtual.

The discussion proceeds as follows. We begin by reviewing the customary meanings for virtuality, and then introduce the additional dimension, drawing on the philosopher Gilles Deleuze's treatment of the virtual. Next, we consider the connection between this latter kind of virtuality and concepts associated with the discursive and narrative construction of reality. With these philosophical foundations in place, we turn to the social and political context in order to consider how the privileges of author-ity, when it comes to creating effective fiction about the future, impact what is in due course actualized as organizational structure and practice. Application to virtuality in the more conventional sense (for example, virtual work and virtual organization) is weighed. The paper concludes with a preliminary consideration of the implications for research practice of viewing IT-enabled change as a form of "authorship."

\section{Extending "The Virtual"}

\subsection{The "Virtual" in the Usual Sense(s)}

The most prevalent notion of the virtual these days is probably that associated with the phrase "virtual reality." And, this meaning has some obvious relevance in studies of organization and work, because of the way in which the electronic mediations that technology provides, for communication and interaction, simulate older, material processes in various ways. In short, people can be said to experience the virtual when they "work in cyberspace"-although, of course, this really entails the skilled deployment of delegates (documents, images, etc.) by means of the technology, rather than a literal occupation by people of cyberspace. Virtuality, of course, has other meanings in the organizational context, which are linked to the 
broader capabilities and effects of information technology. The term refers, for example, to the significantly increased dispersion of work tasks, both geographically and temporally. Also, as reflected in the concept of "the virtual organization," virtuality describes the reordering of relationships between workers and organizations and among organizations. In particular, what makes the virtual organization virtual is the systematic and IT-enabled shift of many tasks and exchanges to a position outside the boundaries of the firm's vertically-integrated structure and away from the traditional employment contract.

These experiential, spatial, temporal, and organizational-structural aspects of virtuality are without question important to understand, and will likely occupy much of the participants' attention at the Portland conference ${ }^{1}$. But also of interest is how organizations and society are creating and entering this new world of the virtual. It will be the argument in this essay that virtuality, in an expanded sense, is crucial to this very accomplishment.

\subsection{The "Virtual" Extended}

What we want to consider is the virtuality reflected in the anticipations and imaginings of the future that precede and shape the actions that people pursue in order to create that very future. This is akin to Heidegger's concept of projection [2], which is commonly rendered as "a throwing of existence ahead of itself" [3]. Deleuze, we find, quite literally labels this virtuality. Deleuze's virtual, however, does not represent the merely possible-which would embrace the myriad (indeed, arguably infinite) worlds entailed in the quotation from Leibniz with which this paper opens. Rather, the virtual is a part of what is real, but not (yet) actual. According to Deleuze, then, mere possibilities must undergo realization in order to become real, while the virtual, being already a part of the real, undergoes actualization in order to produce the objects of the everyday world $[4]^{2}$. Where a technological innovation is concerned, then, the virtual represents for the social collective a "discursive desire" that arises in the cultural circumstances of past and present time that precedes and anticipates the "coming-to-presence" of the focal technology and practice [4]. Hence, the virtual is (per Roe) "not quite the future as such but preceding it and yet still being ahead of the present."

The virtual, moreover, is not simply anticipatory and prescient, but also generative. Because virtuality can be said to help produce the corresponding actuality, a technological innovation can, in an apparent (but only apparent) paradox, be seen necessarily to precede itself. Bucciarelli invokes this phenomenon, in his study of engineering design, when he observes that for much of the design period, "the object the language points to does not exist" [5].

${ }^{1}$ There are additional meanings from physics (e.g., virtual image) and computer technology (e.g., virtual memory) that are farther afield from the concerns of this conference.

${ }^{2}$ Like Proust's characterization of the past, the virtual is "real without being actual, ideal without being abstract." (Noted in the Wikipedia entry for "virtuality"; original source is Volume 7 of Proust's Remembrance of Things Past, "Time Regained.") 
In due course, actualization does take place; that is, the technological innovation becomes an object and practice in everyday space and time. However, the virtual does not vanish at this point but rather inheres in the object that has come into being. This persistence of the virtual is necessary because actualization-or what many of us would liken to "reproduction" [6]-is on going. The continued existence of the actual technology depends on the persistence of the idea that the virtual contains and conveys. Moreover, there is also a "continuous iterative structure" or "virtual-actual circuit" [4] through which the virtual takes up and incorporates the specificities of its actualization and evolves along with it. As such, the virtual is not once-and-for-all but rather dynamic, in the same way that the world it helps to generate is dynamic.

\subsection{The Virtual through Narrative}

The virtual "describes an unsettled region, a zone of potential, that nonetheless contains the real material or content, and above all the idea" [4] of what will become the technology-enabled innovation in organization and/or practice. The actual emerges from the virtual through struggles within the larger culture to formulate in depth and richness of specificity this "discursive desire." As such, a key aspect of the overall collective endeavor is "a struggle for language which would be adequate to the [very] task" [4] of discursively constituting the virtual. Bucciarelli's observation, noted above, also invokes the central place of language in shaping the coming-topresence of the future and actual world. Here, we can find a link between the virtual, in this Deleuzian sense, and the role of narrative in producing socio-technical reality.

That narrative helps to represent and to make sense of passing and prior events is a familiar idea [7-9]. Moreover, action itself is seen to take on narrative qualities [10]. The narrativity of action is at the root of historical understanding, because the traces of action (in documentary evidence, eyewitness reports, direct observation, and so on) can be understood as, and rendered in, narrative form. But narrative is also at the foundation of projected future action, a principle that Fairclough has identified through reference to "imaginaries" in discourse [11]. This points to an inversion of the action-then-account relationship involved when people write history; this is an account-then-action relationship that is fundamental to what happens when people produce history.

Bruno Latour offered a simple but compelling illustration of this inversion, at an IFIP 8.2 meeting a decade ago [12], when he spoke about a pair of acquaintances planning a get-together in London. In making their arrangements, in effect, they coauthored a story. Their collaborative narrative enlisted an array of actors (human and non-human), outlined a sequence of activities, and assigned a variety of essential commitments to themselves and the other actors. Their story, then, became the basis for the actions that would create from the plan a reality in fact.

3 "Discourses not only represent the world as it is (or rather is seen to be), they are also projective, imaginaries, representing possible worlds which are different from the actual world, and tied in to projects to change the world in particular directions." [11] 
This simple tale points to the profound importance that narrative plays in the constitution of the future. We tell stories not only about our past and present, in order to make sense of where and who we are today, but also about the future, in order to bring into being the kinds of futures we desire [13]. Indeed, within constraints people and organizations enact their futures based on narratives of action, events, and identities yet-to-be $[14,15]$. So where a more ambitious undertaking is involved, such as a technology-related organizational change project, the technological innovation in question is quite literally "a fiction seeking to come true" [16]. The manner in which it does so entails a dialectical process in which cycles of discourse and material action transform the world, both as it is built and as it is experienced $[1,11]$.

In certain forms (for example, science fiction), storytelling about the future may entertain only the possible, notwithstanding that it may have larger illuminative, hortatory, or moralistic purposes. On the other hand, narrative offered in the service of the virtual, in Deleuze's sense, is generative in intent and effect. In short, it aims for actualization. It is certainly and necessarily fiction, as Latour implies. However, it entails a kind of fictionalization that is intended to pull the world toward a particular future state. In a temporal reversal of the usual sense of the word, this fictionalization precedes and is, indeed, a prerequisite to actualization. ${ }^{4}$ But of course, the relationship is more complex and nuanced that this. Although the fiction is indeed deployed ahead of action, the production of such fictional narrative, as an on-going and adaptive vehicle for conveying the virtual-actual circuit, iteratively reflects upon and takes up the object reality that is produced as actualization unfolds.

\section{Virtualizing the Virtual: Authority, Participation, and Voice}

To contest a dominant notion of spatio-temporality is to contest the process that produced it and to redefine, in thought, alternative possible worlds of being.

David Harvey [1]

\subsection{Occupying the Virtual}

If the virtual is an "unsettled region" (see Roe's observation quoted above), then the fictionalization we are considering is inherently a subversive challenge to the established order. As such, it works to draw the participants exposed to it away from the familiar and toward a condition of liminality, a twilight zone between the takenfor-granted present and an unknown future.

Liminality means to be situated on a threshold or in a transitional state. Appropriated and enriched by anthropologists (notably Victor Turner), liminality has come to encapsulate transitions, such as rites of passage, in which the normal limits on perception and cognition are transcended, in which established social relations and conventions are relaxed, and in which given identities dissolve $[17,18]$. The

4 Fictionalization usually means to use an actual event as the basis for creating a piece of fiction, such as a play or novel. 
attendant ambiguity and disorientation make liminal territory dangerous, but the associated indeterminancy is also rich in opportunity.

In the context of technology-enabled organizational innovation, the experience of liminality is part and parcel of the encounter with the virtual. The anticipation that occurs at the threshold of actualization induces: liminality in time, between the known present and the uncertain and to-be-transformed future; liminality in place, because of the undoing and redoing of the organizational context of artifacts, structures, and practices; and liminality in identity, as interests, roles, expectations, and skill demands are displaced and shifted.

These modes of liminality characterize all innovation, to some degree. Certainly, where the innovation in question involves the "virtuality" of virtual work and virtual organizations, these modes can be especially worthy of notice. The often-cited effects of engagement with "cyberspace" in translating work in space and time, and on transforming the conceptualization and representation of self, speak to this fact. But it is also important to recognize that such effects are not unique to virtualization in the more conventional sense. 5 Hence, the "virtual" of virtual reality, virtual work, and virtual organization-or what I shall henceforth, for convenience, call "the electronic-virtual"--depends for its actualization on the narrative virtuality we are considering here. The reverse is not the case.

In entertaining the three modes of liminality, and especially the unsettling of identity, we are compelled to move beyond the largely philosophical issue of the relationship between Deleuzian virtuality, discourse, and actualization and begin to entertain the political. This is so, because while the experience of liminality motivates actors to seek resolution through the actualization of a new (and relatively) stable terrain, it can also place those actors in complex, ambiguous, and contentious relationships with one another.

\subsection{The Politics of Virtuality}

In the unsettled, liminal region of the narrative-virtual, the fiction that is- or rather becomes-a real organizational innovation reflects, for a considerable period of time, an uneasy and dynamic mix of discourse and material activity. Precisely because of the power that discourse has in constituting reality, ${ }^{6}$ the narrative-virtual becomes the site of social engagement, as heterogeneous interests struggle with, and for, position and identity.

We must also consider situations in which the expected engagement, and even conflict, does not take place where we might well expect to see it. In these circumstances, the pressing question becomes why certain voices are missing, among those who have a stake in those fictionalizations that point toward the future world. Where the creation of the electronic-virtual, specifically, is the focus of people's

\footnotetext{
${ }^{5}$ Roe, for example, uses the historical emergence of photography in the 19th century to illustrate virtuality in the Deleuzian sense [3].

6 "In sum, texts have causal effects upon, and contribute to changes in, people (beliefs, attitudes, etc.), actions, social relations, and the material world" [11].
} 
discursive attention, the potential scope in the reconstitution of place, time, and identity is such that the issues of who has "voice," and why that is so, become crucial. $^{?}$

These issues are crucial not merely from the point of view of sociological understanding, but also when it comes to practical accomplishment. Harvey remarks [1], "The preservation or construction of a sense of place is . . a an active moment in the passage from memory to hope, from past to future."

Such construction creates an on-going need for adequate "narrative structures" [1] not just for making sense of the present and past but also for fictionalizing the future, in the sense that Latour invokes (see the earlier quote). This is the activity that produces the all-important imaginaries [11] that carry actors to the threshold of the narrative-virtual and henceforth into actualization. As Harvey, quoting Bachelard, states, "Imagination separates us from the past as well as from reality: it faces the future" [1].

In entertaining the question of "adequacy" in imaginative and productive narrative structures, however, it is necessary to recognize that an organization's efforts to fictionalize the future can be better or worse. The effectiveness of the fiction is in part a function of who has voice and access to audience; who, having voice, is entitled to represent or speak on behalf of others; and what implications follow from leaving others bereft of their own narrative. As such, the roles that authority, the structure of participation, and the privilege of representation play in the constitution of the narrative-virtual are central issues for research. ${ }^{8}$

When it comes to the electronic-virtual, there is the commonly held view that the associated innovations in work practice are linked to significant transformations of space and time. In this context, while it is true that "actors are . . "concretely producing their own spacetime" "9 [1], they do so subject to constraints that have been actualized by others. Such constraints arise, in part, through the design of the very technologies used in carrying out the work and mediating workplace interactions, as well as through directed changes in the organization of the work itself. In this we truly witness the "social "production' of space and time" [1]. These outcomes are obviously of considerable interest to scholars of the electronic-virtual, but here we recognize that such designs (and constraints) originate first in the narrative-virtual, to which access in a given social order is uneven and unequal.

The privilege of narrative is constructed and perpetuated to an important degree through and within the narrative process itself, which assigns the requisite authority

${ }^{7}$ Harvey points in particular to the way that "time-space compression" leads to "rootlessness" and "the fear of a loss of identity (understood as an identification with place) as the spacetime coordinates of social life become unstable" [1].

${ }^{8} \mathrm{I}$ am indebted to a reviewer for pointing out that the effectiveness of such fiction must also depend on qualities associated with the content, such as verisimilitude. Here, literary scholarship is likely to be a helpful guide in evaluating effectiveness.

${ }^{9}$ Latour's story, recounted earlier, includes examples of the two participants employing shared understandings and producing joint specifications of space and time. Their naming of specific elements of space and time is integral to creating the prospective and generative "map" that helps to produce the future action. 
as a right of authorship. Moreover, in performing its generative function, the narrative-virtual positions not just those who participate as authors (or designers) but also other actors who fall within the scope of the socio-technical vision being promulgated by the narrative. This authorial positioning, as one aspect of the Deleuzian actualization of reality, is accomplished through the interplay of three functions of the narrative text [11]: identity, by means of which authors situate themselves and others both in the future world and in roles that appear along the path toward its accomplishment [19]; the representational, which discursively casts the future material setting of artifacts, structures, and practices; and action, which leverages language's capacity for defining and fostering commitments [20].

Of course, authorship in the context of world-building is not monolithic. Since creating the future is invariably a collective and dynamic undertaking, so too is the storytelling associated with it. Those having voice, or author-ity, will produce and amend their own storylines in ways that respond inter-textually [11] to the stories of others. Notwithstanding the collective nature of the enterprise, however, the distribution of author-ity for the narrative-virtual remains uneven and problematic.

This is a matter not simply of academic interest but also of social and ethical import. As workers and other actors subjected to IT-enabled change confront the liminality of identity, their opportunities and abilities to put themselves into the stories they tell about their own work can have a crucial bearing on the qualities of the community that results. Harvey remarks [1]:

For if ... we get at the end . . . a result which is the product of our imaginations at the beginning, then how we imagine communities and places of the future and how we talk about them becomes part of the jigsaw of what our future can be . . . And even if . . . there is many a slip between imagination and realization and a whole host of unintended consequences to be countered and discounted on the path, the question of how we imagine the future of places and with what seriousness we invest in it is always on the agenda.

When he concludes, then, that "our future places are for us to make" [1], the hope he expresses depends on the inclusiveness of the "us" and the qualities of the collective fictionalizing we have considered here. Neither can be taken for granted. At the same time, however, this invites the question of the scholar's potential contribution to this process. We consider that issue next.

\section{Narrative Virtualization and Critical Scholarship}

How can one reduce the great peril, the great danger with which fiction threatens our world?

Michel Foucault [21]

We are all familiar with engineering metaphors for the creation and implementation of information systems. These have been facilely applied in scholarly analyses of the design and construction of application software (for 
example, "software engineering"), databases, and supporting technology infrastructure (for example, "network architecture"). And engineering metaphors have been extended more broadly, as in "process (re)engineering," to the reshaping of organizational form and participation. The engineering framing in the domain of IT management scholarship has encouraged the pursuit of research that involves building and testing models replete with factors and causal relationships that might provide, in projects, predictability and control over the particulars of technical and organizational design and, in operations, the smooth and steady conduct of the IT enterprise.

By contrast, this essay invites the use of a different, if potentially complementary, metaphor for information systems practice - that of authorship. And yet, it is something more than metaphor. As we have argued here, narrative activity is indispensable in the effort to create the future. How, then, might we need to supplement our more conventional strategies for analysis? What ought scholarly inquiry to look like, when narrative virtuality becomes a subject of consideration? And what, from an applied perspective, would be a meaningful contribution by scholars to the constitution of future worlds? Here I can only begin to suggest some basic directions, and so I leave it mainly for further discussion to explore more fully the possibilities.

I will start with the quote from Foucault, given above. ${ }^{10}$ In this bit of unabashed hyperbole, Foucault invokes the power of fiction to transform reality, much as we have been pondering in this essay. The rampant significations of texts, loosed upon the world, tend not to rest with possibilities merely, but to extend themselves to the narrative-virtual and then to the actual, changing the material ground upon which future significations arise. However, it is precisely in the construction of the author and authorship that the power of fiction can be constrained [21]:

[The author] is a certain functional principle by which, in our culture, one limits, excludes, and chooses; in short, by which one impedes the free circulation, the free manipulation, the free composition, decomposition, and re-composition of fiction ... The author is therefore the ideological figure by which one marks the manner in which we fear the proliferation of meaning.

The author - which for our purposes need not be an individual or singular author in the conventional literary sense but could be, for example, an organizational or institutional actor-becomes the means of localizing, relativizing, and even transfixing the significations of a text, which might otherwise roam the world freely and command inordinate sway over the narrative-virtual. Thereby anchored to context, the text's substantive claims to represent, and hence instantiate, reality can be related to its associated regime of truth [22], that is, its particular "institutional infrastructure for the production and circulation of truth claims" [23]. The scholar, then, enjoys an advantageous position from which to investigate and expose the

${ }^{10}$ I must thank another reviewer for recommending consideration of Foucault's work on the concept of the author. The quote alone made following this advice highly worthwhile. 
interdependencies among institutional constraints and power and the language deployed in efforts to (re)constitute the world. Of particular interest, perhaps, is the manner in which the possibilities for even "visionary" authorship are shaped and delimited by existing discursive formations [24].

I believe this contextualization of authorship provides one way to answer Czarniawska's call for organizational scholars to engage in "literary work" [25], "Human sciences should join philosophy, art, and history: "modes of experience in which a truth is communicated that cannot be verified by the methodological means proper to science' (quoting Gadamer [26])." In a similar vein Zald, when he outlines the benefits to be gained from a fuller rapprochement in organizational studies between the social sciences and the humanities, recommends attention to literary theory and history, both streams of inquiry that speak to the creation of stories [27]. He calls, specifically for the use of narrative and literary techniques, "to aid policy analysts in constructing better criteria for evaluating policy alternatives. Essentially, the techniques . . . allow one to evaluate the many story lines and voices surrounding a policy issue and thereby to suggest alternatives." [27]. And, he remarks, "For organizational studies, narrative analysis provides a tool for a deeper understanding of the decision-choice process." [27] To this we might add, also, the sense-making process, in cognizance of Weick's observation that "what is needed in sensemaking is a good story" [15].

But this in turn transports us, as scholars, from an endeavor focused on understanding and explanation to one concerned with evaluation. What are the standards for determining what, in fact, is a "good story" or effective fictioncompelling and legitimate discourse [11] that can constitute the narrative-virtual? What are the conditions and processes associated with the creation of such fiction? Among other issues, the matter of participation and voice introduced here would clearly deserve attention, as would the responsibilities of management to help foster favorable circumstances for narrative. However, it is not clear that our discipline is, as yet, well-equipped to conduct this kind of evaluation. In this regard, research on the narrative-virtual might be envisioned to look rather like literary criticism, as Czarniawska and Zald hint. ${ }^{11.12}$

Amplified by criticism, our science would engage in meta-narration about our subjects' fictionalizations, as the latter do their work to bring-to-presence the sociotechnical actuality that becomes the expression of their authors' ambitions, dreams,

11 "Literary criticism is the study, discussion, evaluation, and interpretation of literature," where literature, under the sway of contemporary cultural studies, "can potentially refer to any use of language" and a great variety of "texts" (Wikipedia, entries for literary criticism and literary theory).

${ }^{12}$ There may be something to be said, also, for scholars creating their own fictions that could be usefully deployed in constituting the future (Liz Davidson, p.c.). This appears to be a part of what Latour is suggesting, when he writes that we should "count on the human sciences offering the actors multiple and rapidly revised versions that allow us to understand the collective experience in which we are all engaged. All the '-logies,' graphies,' and '-nomies' then become indispensable if they serve to propose constantly, to the collective, new versions of what it might be" [28]. 
and imaginings. Such meta-narration would entail the assessment of how well, and by what manner, the fictions created by organizationally-situated actors transform the merely possible, in Deleuze's terms, into the virtual. That is, what does fictionalization need in order to convince, induce commitments, and ultimately contribute to the constitution of the material world? In short, our new literary research, in taking our subjects' storytelling as a process subject to systematic and critical study, would become a science of possible worlds.

\section{Conclusion}

Jose Arcadio Buendia did not succeed in deciphering the dream of houses with mirror walls until the day he discovered ice. Then he thought he understood its deep meaning. He thought that in the near future they would be able to manufacture blocks of ice on a large scale from such a common material as water and with them build the new houses of the village. Macondo would no longer be a burning place, where the hinges and doorknockers twisted with the heat, but would be changed into a wintry city. ${ }^{13}$

Gabriel Garcia Marquez [31]

As scholars of organizations who are especially concerned with innovation, our engagement with our subject matter necessarily carries us beyond studying the past merely in order to understand how things have come about. It sets us instead on the transcendent path of producing knowledge that is useful in effecting change. Of course that also puts us in the position of attempting to make knowledge claims about the future in the curious circumstances where the world that would provide the surest evidence of our claims does not yet exist. But we do not have to fall back on our grasp of the past and rely on the paradoxical hope that the future will be enough like the past to allow us to make predictions. To the contrary, our research subjects' own activities, in predicting and indeed constructing the future, point the way out of this bind.

When it comes to the manner in which our subjects have constituted, and continue to evolve, such innovative forms and practices as virtual organizations and virtual work, I have argued here that attention to the virtual in another and more fundamental sense can provide our scholarly community with opportunities to contribute, in partnership with our subjects, to the creation of future worlds and our respective identities within them. That species of virtuality, the narrative-virtual,

13 I include this final quote in a somewhat mischievous nod to the literary. As an example of the magical-realist genre, it represents one "narrative mode, or a way of thinking in its most expansive form" [29]. In fact, magical realism is a genre that is specifically noted for its capacity to induce liminality: Magical realism "is a mode suited to exploring - and transgressing-boundaries, whether the boundaries are ontological, political, geographical, or generic", and it "often facilitates the fusion or coexistence of possible worlds, spaces, systems that would be irreconcilable in other modes of fiction .... The propensity of magical realist texts to admit a plurality of worlds means that they often situate themselves on liminal territory between or among these worlds" [30]. 
provides the foundation for the (re)constitution of work and organization in ways that can have the properties more commonly and popularly associated with the term "virtual." But our engagement as scholars in the narrative-virtual will require us to expand our vision of our own practice and, hence, to fictionalize about our own future in the way that our subjects must, and do, about their own.

\section{Acknowledgements}

The author thanks the three anonymous reviewers for their constructive comments. The creation of this paper has also benefited significantly from conversations with Erica Wagner and Liz Davidson. The early development of some of the ideas included here received encouragement and support from workgroup participants at the November 2005 Workshop on Designing Information and Organizations with a Positive Lens, Weatherhead School of Management, Case Western Reserve University. In connection with that, I particularly thank Richard Buchanan and Dick Boland.

\section{References}

1. D. Harvey, Justice Nature and the Geography of Difference (Blackwell, Oxford, UK, 1996).

2. M. Heidegger, Being and Time, translated by J. Macquarrie and E. Robinson (Basil Blackwell, Oxford, 1973).

3. P. Roe, That-Which-New Media Studies-Will-Become, Fibreculture Journal, Issue 2 (2003); http://journal.fibreculture.org/issue2/issue2_roe.html.

4. G. Deleuze, Difference and Repetition, translated by P. Patton (Athlone, London, 1994).

5. L. L. Bucciarelli, Designing Engineers (MIT Press, Cambridge, MA, 1994).

6. A. Giddens, The Constitution of Society (University of California Press, Berkeley, CA, 1984).

7. J. Bruner, Actual Minds, Possible Worlds (Harvard University Press, Cambridge, MA, 1986).

8. J. Bruner, Acts of Meaning (Harvard University Press, Cambridge, MA, 1990).

9. D.E. Polkinghome, Narrative Knowing and the Human Sciences (State University of New York Press, Albany, NY, 1988).

10. P. Ricoeur, The Model of the Text: Meaningful Action Considered as Text, in: Paul Ricoeur: Hermeneutics and the Human Sciences, edited by J.B. Thompson (Cambridge University Press, Cambridge, 1981), pp. 197-221.

11. P. N. Fairclough, Analysing Discourse: Textual Analysis for Social Research (Routledge, UK, 2003).

12. B. Latour, Social Theory and the Study of Computerized Work Sites, in: Information Technology and Changes in Organizational Work, edited by W.J. Orlikowski, G. Walsham, M.R. Jones, and J.I. DeGross (Chapman \& Hall, London, 1996), pp. 295-307.

13. R. J. Boland, Jr., and R.V. Tenkasi, Perspective Making and Perspective Taking in Communities of Knowing, Organization Science 6(4), 350-372 (1995). 
14. B.T. Pentland, Building Process Theory with Narrative: From Description to Explanation, Academy of Management Review 24(4), 711 -724 (1999).

15. K.E. Weick, Sensemaking in Organizations (Sage, Thousand Oaks, CA, 1995).

16. B. Latour, Aramis or the Love of Technology (Harvard University Press, Cambridge, MA, 1996).

17. V. Turner, The Ritual Process: Structure and Anti-structure (Aldine, Chicago, 1969).

18. V. V. Turner, From Ritual to Theater: The Human Seriousness of Play (PAJ Publications, New York, 1982).

19. N.C. Ramiller, Applying the Sociology of Translation to a System Implementation in a Lagging Enterprise, Journal of Information Technology Theory \& Applications 7(1), (2005).

20. J.L. Austin, How to Do Things with Words (Harvard University Press, Cambridge, MA, 1962).

21. M. Foucault, What Is an Author?, in: The Foucault Reader, edited by P. Rabinow (Pantheon Books, New York, 1984), pp. 101-120.

22. M. Foucault, Power/Knowledge: Selected Interviews and Other Writings, 1972-1977, edited by C. Gordon (Pantheon, New York, 1980).

23. L.D. Introna and L. Whittaker, Journals, Truth and Politics: The Case of MISQ, in: Information Systems Research: Relevant Theory and Informed Practice, edited by B. Kaplan, D.P. Truex, D. Wastell, A.T. Wood-Harper, and J.I. deGross, (Springer-Kluwer, Dordrecht, 2004), pp. 103-120.

24. M. Foucault, The Archaeology of Knowledge, and the Discourse on Language, translated by A.M. Sheridan Smith (Pantheon Books, New York, 1972).

25. B. Czarniawska, Narratives in Social Science Research (Sage, London, 2004).

26. H-G. Gadamer, Truth and Method (Continuum, New York, 1960/1975).

27. M.N. Zald, More Fragmentation? Unfinished Business in Linking the Social Sciences and the Humanities, Administrative Science Quarterly 41, 251-261 (1996).

28. B. Latour, Politics of Nature: How to Bring the Sciences into Democracy (Harvard University Press, Cambridge, MA, 2004).

29. M.A. Bowers, Magic(al) Realism (Routledge, London, 2004).

30. L.P. Zamora and W.B. Faris, Introduction: Daiquiri Birds and Flaubertian Parrot(ie)s, in: Magical Realism: Theory, History, and Community, edited by L.P. Zamora and W.B. Faris (Duke University Press, Durham and London, 1995), pp. 1-11.

31. Gabriel Garcia Marquez, One Hundred Years of Solitude, translated by G. Rabassa (Harper \& Row, New York, 1970). 


\begin{abstract}
About the Author
Neil Ramiller is an Associate Professor in Information Systems Management and the Ahlbrandt Professor in the Management of Innovation \& Technology at Portland State University's School of Business Administration. He holds a Ph.D. from UCLA's Anderson School of Management. His primary research activities address the management of information-technology innovations, with a focus on the role that rhetoric, narrative, and discourse play in shaping innovation processes within organizations and across institutional fields. He also conducts work on the social construction of information technology scholarship, and the implementation of the "linguistic turn" in information technology studies. Dr. Ramiller has presented his work at a variety of national and international conferences, and published articles in a number of journals, including MIS Quarterly, Information \& Organization, Information Technology \& People, Organization Science, The Journal of Management Information Systems, Communications of the AIS, Information Systems Research, the Journal of Information Technology Theory \& Applications, and the Journal of Information Systems Education. His paper with E. Burton Swanson, "Innovating Mindfully with Information Technology," won the 2004 Best Paper Award from MIS Quarterly. In 2006, Dr. Ramiller's paper "Hype! Toward a theory of exaggeration in information technology innovation" was awarded the Best Paper prize from the Organizational Communications \& Information Systems (OCIS) division of the Academy of Management. Dr. Ramiller is an associate editor for MIS Quarterly and a member of the editorial board for Information Technology \& People.
\end{abstract}

